\title{
Facial Eco-Friendly Synthesis of Copper Oxide Nanoparticles Using Chia Seeds Extract and Evaluation of Its Electrochemical Activity
}

\author{
Noha Al-Qasmi iD
}

Citation: Al-Qasmi, N. Facial Eco-Friendly Synthesis of Copper Oxide Nanoparticles Using Chia Seeds Extract and Evaluation of Its Electrochemical Activity. Processes 2021, 9, 2027. https://doi.org/ $10.3390 /$ pr9112027

Academic Editors: Douglas J. H. Shyu and Yih-Yuan Chen

Received: 7 October 2021

Accepted: 11 November 2021

Published: 13 November 2021

Publisher's Note: MDPI stays neutral with regard to jurisdictional claims in published maps and institutional affiliations.

Copyright: (C) 2021 by the author. Licensee MDPI, Basel, Switzerland. This article is an open access article distributed under the terms and conditions of the Creative Commons Attribution (CC BY) license (https:/ / creativecommons.org/licenses/by/ $4.0 /)$.
Chemistry Department, Faculty of Science, Taif University, Al-Hawiah, Taif City 11099, Saudi Arabia; noha.alqasmi@tu.edu.sa

\begin{abstract}
In the current study, copper oxide nanoparticles ( $\mathrm{CuO}$ NPs) were synthesized using chia seed extract in a simple, rapid, and eco-friendly manner for the first time. The synthesized $\mathrm{CuO}$ NPs were characterized using different analytical techniques. The images of field emission scanning electron microscopy revealed that the $\mathrm{CuO}$ NPs were triangular and pyramid in structure, with a mean particle size of $61.5 \mathrm{~nm}$. The absorption peak of the synthesized $\mathrm{CuO}$ NPs was measured using ultraviolet-visible spectroscopy and was recorded at a wavelength of $291 \mathrm{~nm}$. The results of energydispersive X-ray analysis confirmed that the CuO NPs synthesized using chia seed extract yielded high-purity $\mathrm{CuO}$ NPs. Moreover, the X-ray diffraction analysis indicated the highly crystalline nature of the CuO NPs, and the X-ray photoelectron spectroscopy results indicated that the CuO NPs were prepared successfully. Additionally, electrochemical impedance spectroscopy measurements revealed excellent electrocatalytic conductivity and fast electron transfer at the electrode/electrolyte interface of the synthesized CuO NP-modified glassy carbon electrode.
\end{abstract}

Keywords: green synthesis; $\mathrm{CuO}$ nanoparticles; chia extract; metal oxide; characterization

\section{Introduction}

In recent decades, nanoscale materials (1-100 $\mathrm{nm}$ ) have been utilized for a diverse range of applications owing to their distinctive chemical, mechanical and electrochemical properties, which clearly distinguish these materials from those with large molecules [1-4]. Metal oxide nanoparticles (MONPs) such as $\mathrm{TiO}_{2}, \mathrm{ZnO}, \mathrm{NiO}, \mathrm{Fe}_{2} \mathrm{O}_{3}$, and $\mathrm{CuO}$ have been applied in the biological, medical, and environmental fields [5-10]. Therefore, different chemical and physical methodologies have been developed to prepare them. Such synthetic methods have, however, generated other challenges for scientific communities, as they are time-consuming and expensive; moreover, they also involve the release of toxic reagents into the environment, causing significant pollution [11-14]. Therefore, to mitigate these issues, researchers have focused on employing alternative eco-friendly approaches, such as the usage of plant extracts or microorganisms, to synthesize MONPs [15-21].

Copper oxide NPs (CuO NPs) are regarded as unique and inexpensive MONPs. They have a small bandgap $(\sim 1.7 \mathrm{eV})$ and high surface area, in addition to exhibiting high catalytic activity [2,22]. Consequently, they are widely used in the environmental, industrial, medical, chemical, and physical fields [19,23,24]. For example, they are employed as catalysts and antimicrobial agents; they are also used in solar energy systems, electrochemical and gas sensors, and for water purification [25-27].

Nevertheless, several chemical methods have been investigated to synthesize $\mathrm{CuO}$ NPs using toxic and corrosive reducing agents such as ethylene glycol, hydrazine, and sodium tartrate [28,29]. In addition, microorganisms, e.g., yeast, bacteria, and fungi have been utilized to prepare $\mathrm{CuO}$ NPs in the literature [30,31]. To date, there has been an increase in reports on the synthesis of $\mathrm{CuO}$ NPs using plant extracts such as Gloriosa superba L., Aloe Vera leaf, coffee powder, and fruit peel extract [23,32-34]. Thus, green synthetic 
$\mathrm{CuO}$ NPs using plant extracts are considered a good alternative to hazard reagents, high costs, and time-consuming methods.

This is, to our knowledge, the first study on the synthesis of CuO NPs using chia seed extract, which reports it as a safe, efficient, rapid, and eco-friendly method. Chia (Salvia hispanica L.) is a member of the Lamiaceae family, typical of an annual herbaceous plant. Further, it is well-known worldwide owing to its medicinal properties and significant benefits to human health. It is considered a rich source of dietary fiber, oil, and omega-3linolenic acid. However, the natural antioxidants, such as flavonoids, phenolic compounds, caffeic acid, kaempferol, and chlorogenic acid [16] as shown in Figure 1, contained in chia seeds extract play an important role in the synthesis of these CuO NPs; specifically, they help eliminate any toxic reagents and are inexpensive. These compounds also act as capping and reducing agents to successfully reduce copper ions to CuO NPs in a facile manner. Therefore, the aim of this work is to synthesize CuO NPs using a simple, eco-friendly route and perform chemical and electrochemical characterizations of the synthesized nanoparticles.<smiles>O=C(/C=C/c1ccc(O)c(O)c1)O[C@@H]1C[C@](O)(C(=O)O)[C@@H](O)[C@H](O)[C@H]1O</smiles><smiles>O=C(O)/C=C/c1ccc(O)c(O)c1</smiles>

caffeic acid<smiles>O=c1c(O)c(-c2ccc(O)cc2)oc2cc(O)cc(O)c12</smiles><smiles>CCCCCCCCCCC=CC=CC(=O)O</smiles>

kaempferol

ferulic acid<smiles>O=c1c(O)c(-c2ccc(O)c(O)c2)oc2cc(O)cc(O)c12</smiles>

Figure 1. The chemical structure of some antioxidant compounds in chia seed extract.

\section{Experimental}

\subsection{Materials and Preparation of Seed Extracts}

Copper chloride $\left(\mathrm{CuCl}_{2} \cdot 2 \mathrm{H}_{2} \mathrm{O}\right)$ was purchased from Sigma Aldrich Chemicals Ltd. and used as received; additionally, double-distilled water was used in this study. Chia seeds (Salvia hispanica L.) were purchased from a local market and first washed using tap 
water. Then, they were washed using double-distilled water to remove dust particles and impurities. They were subsequently dried under ambient conditions for three days. The seed extract was prepared by mixing $5 \mathrm{~g}$ of dried seeds with $100 \mathrm{~mL}$ of double-distilled water and boiling at $50{ }^{\circ} \mathrm{C}$ for $20 \mathrm{~min}$. The seed extract was filtered and retained for further experiments.

\subsection{Green Synthesis of the $\mathrm{CuONPS}$}

$\mathrm{CuCl}_{2} \cdot 2 \mathrm{H}_{2} \mathrm{O}(10 \mathrm{~g})$ was dissolved in double-distilled water $(100 \mathrm{~mL})$ in a flask. The solution was then boiled on a hot plate for $5 \mathrm{~min}$ at $30^{\circ} \mathrm{C}$. Then, $20 \mathrm{~mL}$ of the seed extract was added to the salt solution, along with vigorous stirring. The solution color changed from light green to dark brownish during the reaction, indicating the formation of $\mathrm{CuO}$ NPs. Then, the solution was centrifuged at $15000 \mathrm{rpm}$ for $20 \mathrm{~min}$. The synthesized $\mathrm{CuO}$ NPs were washed several times with double-distilled water and dried for $12 \mathrm{~h}$ in the oven at $80^{\circ} \mathrm{C}$. After that, the dried NPs were annealed in a muffle furnace at $300{ }^{\circ} \mathrm{C}$ for $3 \mathrm{~h} \mathrm{[21]}$ to achieve stable $\mathrm{CuO}$ NPs. Finally, the synthesized $\mathrm{CuO}$ NPs were stored in a glass vial for characterization.

\subsection{Characterization of the Synthesized $\mathrm{CuO} N \mathrm{NS}$}

The morphological study and elemental composition of the synthesized $\mathrm{CuO}$ NPs were examined using field emission scanning electron microscopy (JSM-7100F FESEM JEOL USA) and energy-dispersive X-ray (EDX) analysis. The X-ray diffraction (XRD) patterns of the powdered $\mathrm{CuO}$ NPs were accomplished using a Scanting XDS 2000 diffractometer equipped with a $\mathrm{Cu} \mathrm{K} \alpha$ radiation source. The absorption band of the synthesized $\mathrm{CuO}$ NPs was obtained using an ultraviolet-visible-near infrared (UV-vis-NIR) spectrometer (Lambda 750, Perkin Elmer) in the wavelength range of 200-800 nm. X-ray photoelectron spectroscopy (XPS) analysis was performed using a PHI 5000VersaProbeII, ULVAC-PHI Inc. instrument. Electrochemical impedance spectroscopy (EIS) was performed at $25^{\circ} \mathrm{C}$ using an SP-200 potentiostat/galvanostat (Bio-Logic Science Instruments, France) equipped with EC-Lab software for data analysis. Three electrodes were utilized, including a glassy carbon (GC) electrode or the synthesized CuO NP-modified GC electrode as the working electrode, an $\mathrm{Ag} / \mathrm{AgCl}$ electrode (saturated $\mathrm{KCl}$ ) as the reference electrode, and a Pt electrode as the counter-electrode. The Nyquist plots were recorded in $0.1 \mathrm{~mol} \mathrm{~L}^{-1} \mathrm{KCl}$ containing $2 \mathrm{mmol} \mathrm{L}^{-1}\left[\mathrm{Fe}(\mathrm{CN})_{6}\right]^{3-/ 4-}$, at the open-circuit potential over a frequency range of $0.1 \mathrm{~Hz}$ to $100 \mathrm{kHz}$ under an AC amplitude of $10 \mathrm{mV}$.

\section{Results and Discussion}

\subsection{Study of the Morphology of $\mathrm{CuO}$ NPs}

The surface morphology of the synthesized $\mathrm{CuO}$ NPs using chia seed extract was analyzed using FESEM, as shown in Figure 2. The FESEM images (Figure 2a-d) clearly show a well-defined triangular pyramid shape with different sizes of the synthesized $\mathrm{CuO}$ NPs. It is also evident that the CuO NPs agglomerate at low and high magnifications. Overall, the average particle size of the CuO NPs synthesized using chia seed extract was approximately $61.5 \mathrm{~nm}$. 


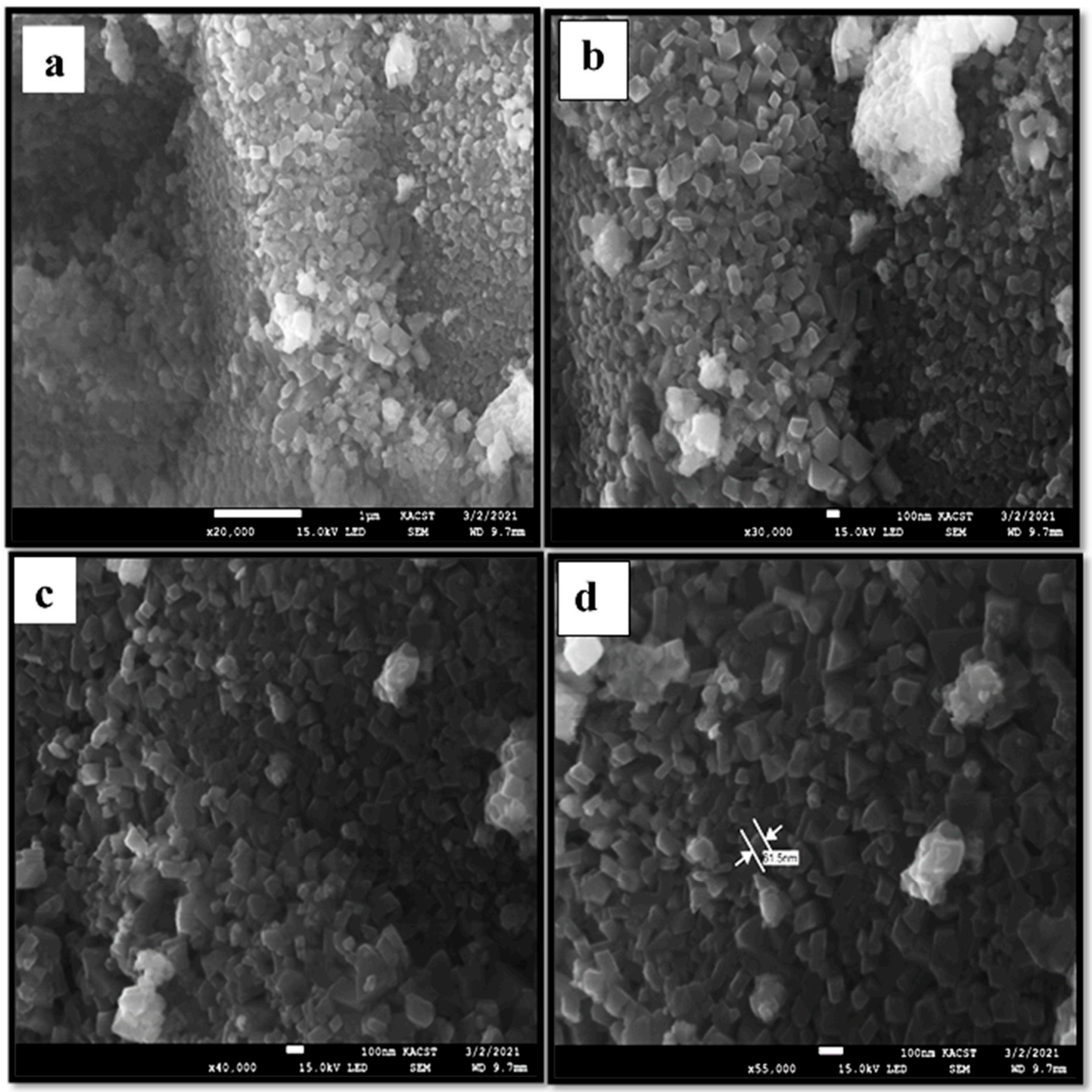

Figure 2. FESEM images of the synthesized CuO NPs at different magnifications.

\subsection{EDX Spectrum}

EDX analysis of the synthesized $\mathrm{CuO}$ NPs was used to confirm their elemental composition and purity (Figure 3). The copper peaks centered on $1 \mathrm{keV}$ and $8 \mathrm{keV}$ and the oxygen peak centered on $0.5 \mathrm{keV}$ [21], as shown in Figure 3. The weight present compositions of $\mathrm{Cu}$ and $\mathrm{O}$ were $79.9 \%$ and $20.1 \%$, respectively. The EDX spectrum revealed the high purity of the synthesized $\mathrm{CuO}$ NPs. 


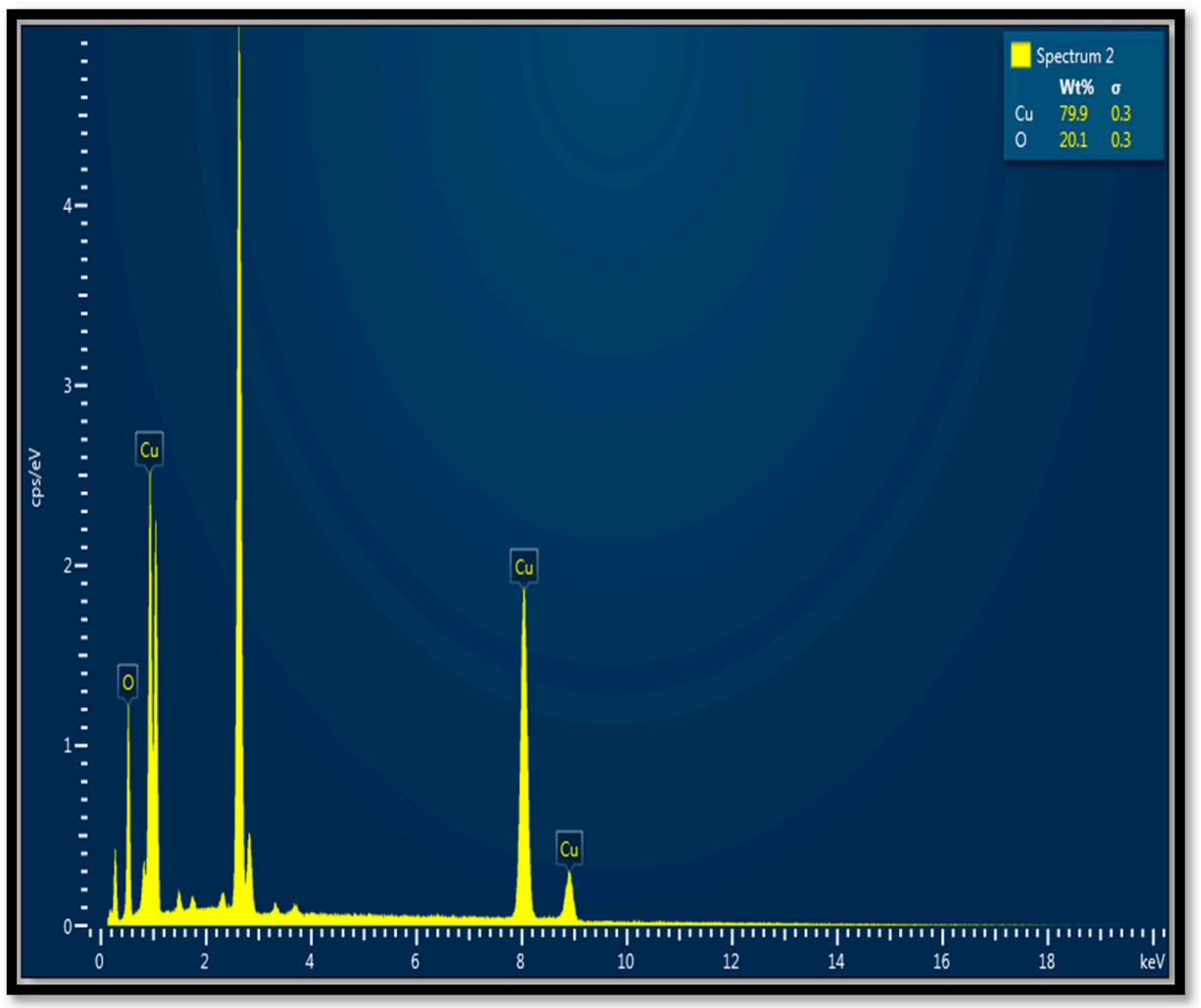

Figure 3. EDX spectrum of the synthesized CuO NPs.

\subsection{X-ray Diffraction (XRD)}

Figure $4 a, b$ displays the XRD analysis of the experimental synthesized $\mathrm{CuO}$ NPs using chia seed extract and a comparison with its simulation data. According to the XRD pattern, there are significant diffraction peaks at $2 \theta\left(32.4^{\circ}, 35.5^{\circ}, 38.6^{\circ}, 48.7^{\circ}, 53.4^{\circ}, 58.1^{\circ}, 61.2^{\circ}\right.$,

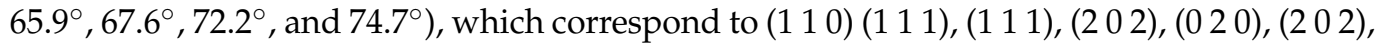
(1 13 3), (0 2 2), (2 20 ), (3 12 2) and (2 03 3) planes. These diffraction peaks are interrelated with the Joint Committee on Powder Diffraction Standards (JCPDS) database. Further, from the distinct sharp peaks in the CuO NPs spectrum, the average crystalline size was estimated from Debye Scherer's equation and found to be approximately $46-55 \mathrm{~nm}$. Comparing the experimental synthesis of $\mathrm{CuO}$ NPs to the respect simulation data, there is no variation in peak positions. These results demonstrate that the $\mathrm{CuO}$ NPs were free of any impurities. Additionally, the results indicate the successful preparation of the monoclinic CuO NPs using chia seed extract, and the highly crystalline nature of the prepared NPs [21].

\subsection{UV-Vis Analysis:}

The UV-vis spectrum was obtained in the wavelength range of 200-800 nm (Figure 5). During the chemical reaction between chia seed extract and copper chloride salt, the color changed from light green to dark brownish, indicating that the reaction was successful. This result was further confirmed by the distinct broad peak at approximately $291 \mathrm{~nm}$ [20], indicating the formation of $\mathrm{CuO}$ NPs. Moreover, as reported in the literature $[16,35]$, the absorbance of chia seed extract and copper chloride salt were recorded in the range $400-450 \mathrm{~nm}$ and $235 \mathrm{~nm}$, respectively.

However, the mechanism of the formation of and reduction in CuO NPs could be attributed to the ability of free radicals in flavonoids, phenolic compounds, and chlorogenic acid in chia seeds extract, to reduce copper ions to $\mathrm{CuO}$ NPs. These organic compounds also might act as capping and stabilizing agents, which play a role in the crystalline growth of $\mathrm{CuO}$ NPs into a well-defined triangular pyramid shape [16]. 


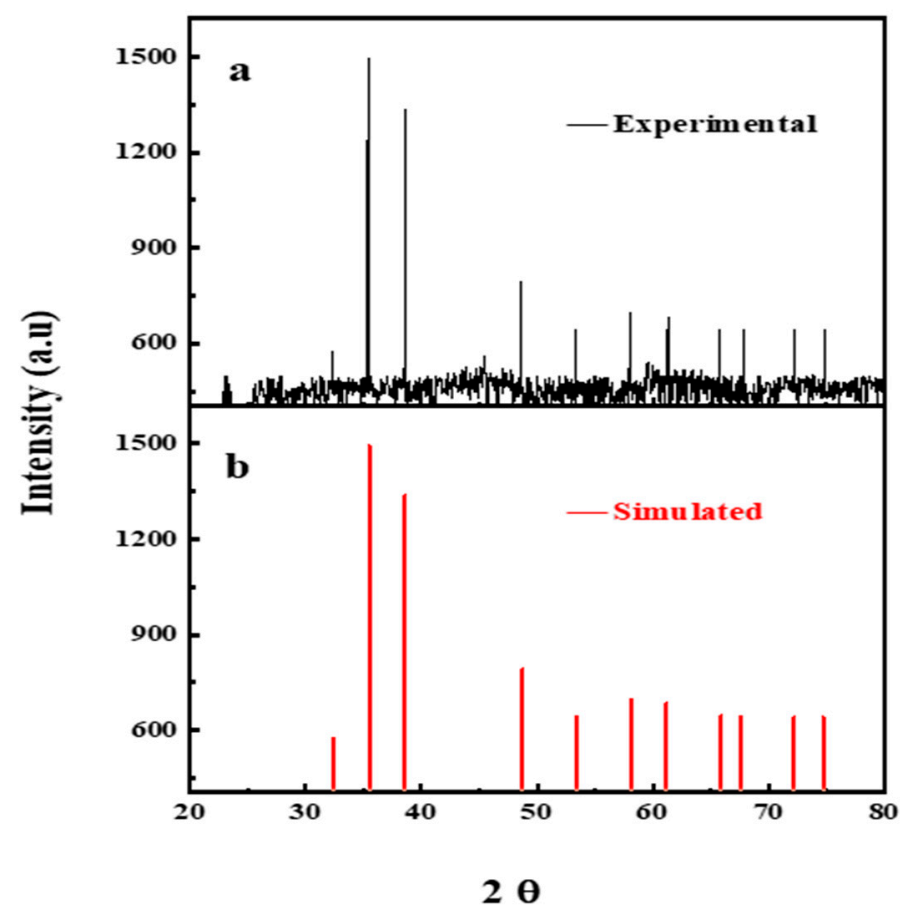

Figure 4. XRD spectrum of (a) of the synthesized CuO NPs experimentally and (b) in comparison with the simulated peaks.

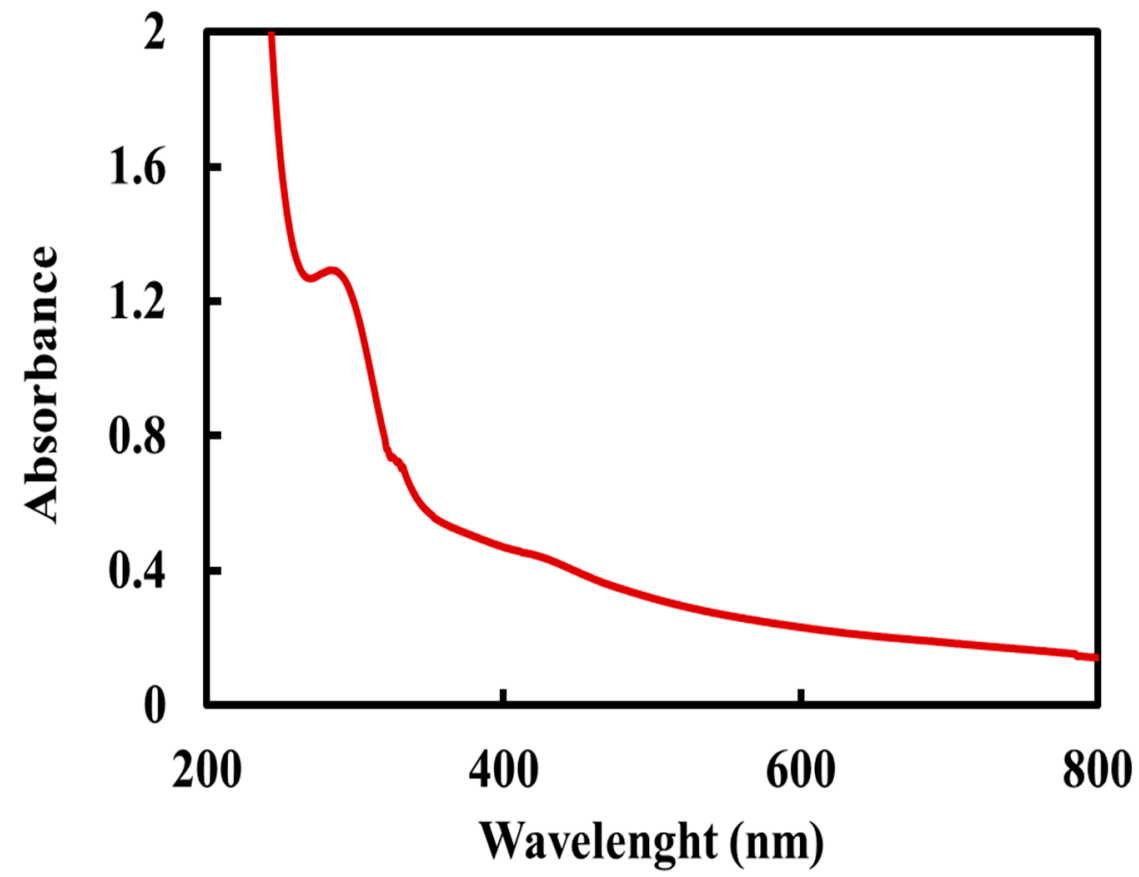

Figure 5. UV-vis absorption spectrum of the synthesized CuO NPs.

\subsection{X-ray Photoelectron Spectroscopy (XPS)}

XPS analysis was utilized to identify the elemental composition of the synthesized $\mathrm{CuO}$ NPs. Figure 6a,b shows their XPS spectra. The spectra were calibrated considering the binding energy (BE) of $284.5 \mathrm{eV}$ for a C 1s electron. According to the XPS spectra, the BEs of 938.5 and $957.5 \mathrm{eV}$ match $\mathrm{Cu} 2 \mathrm{p}_{3 / 2}$ and $\mathrm{Cu} 2 \mathrm{p}_{1 / 2}$, respectively, and the $\mathrm{BE}$ at $535 \mathrm{eV}$ match $\mathrm{O} 1 \mathrm{~s}[36,37]$. This result revealed that the synthesized material obtained comprises pure $\mathrm{CuO}$ NPs without any impurities, and the EDX results were in good agreement. 

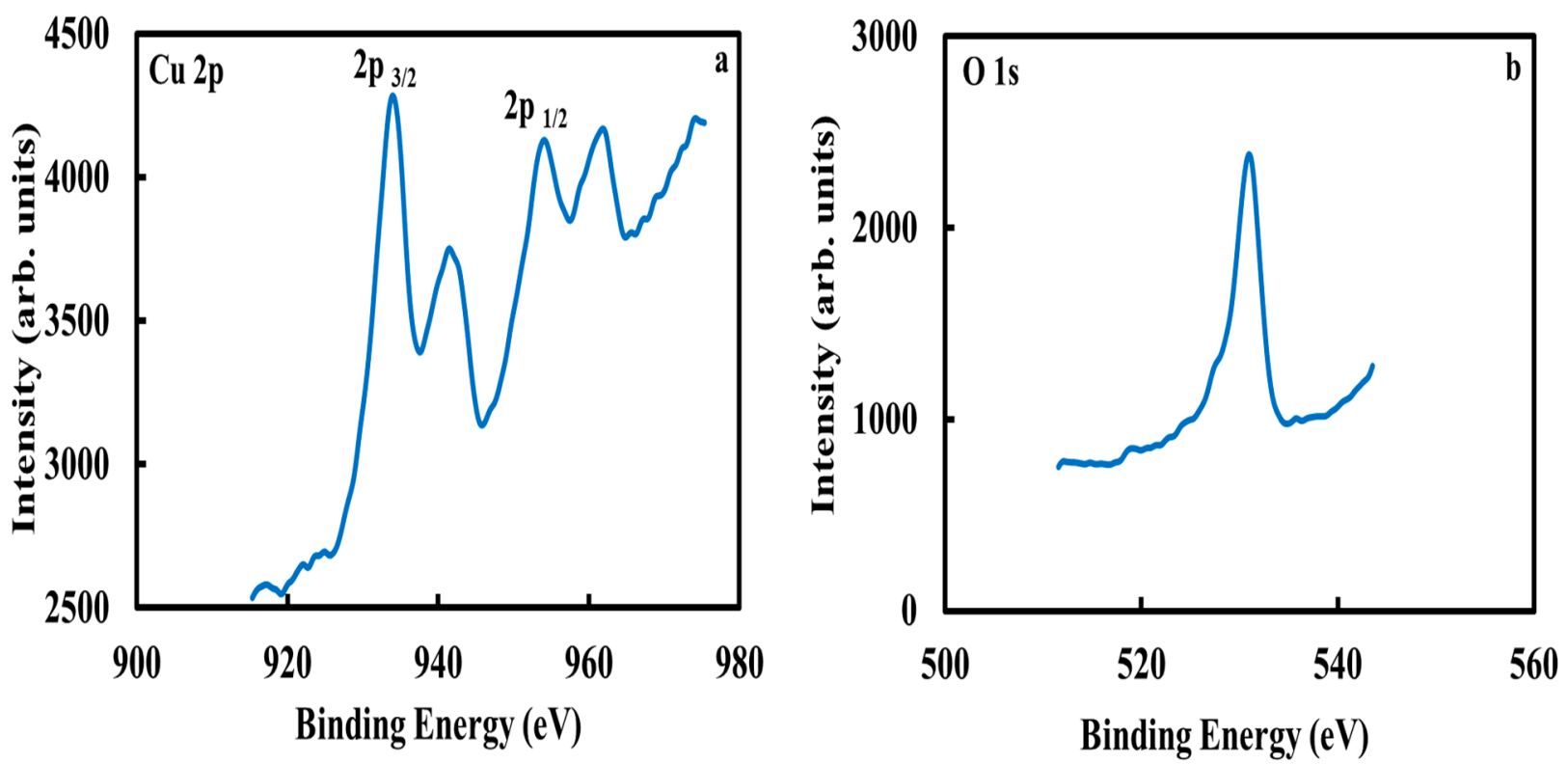

Figure 6. $(\mathbf{a}, \mathbf{b})$ XPS spectra of the synthesized CuO NPs.

\subsection{Electrochemical Impedance Spectroscopy (EIS):}

Figure 7 shows the EIS spectra of the bare GC electrode and the synthesized CuO NPmodified GC electrode. As depicted in the Nyquist plot form, there was a decrease in the semi-circular region's diameter after modification of the GC electrode with the synthesized $\mathrm{CuO}$ NPs, as compared with that of the bare GC electrode. The lower charge transfer resistance of the synthesized $\mathrm{CuO}$ NP-modified GC electrode enhanced the electrical conductivity and electron transfer at the electrode/electrolyte interface. Therefore, this result indicates that the synthesized $\mathrm{CuO}$ NPs may be utilized as electrochemical sensors.

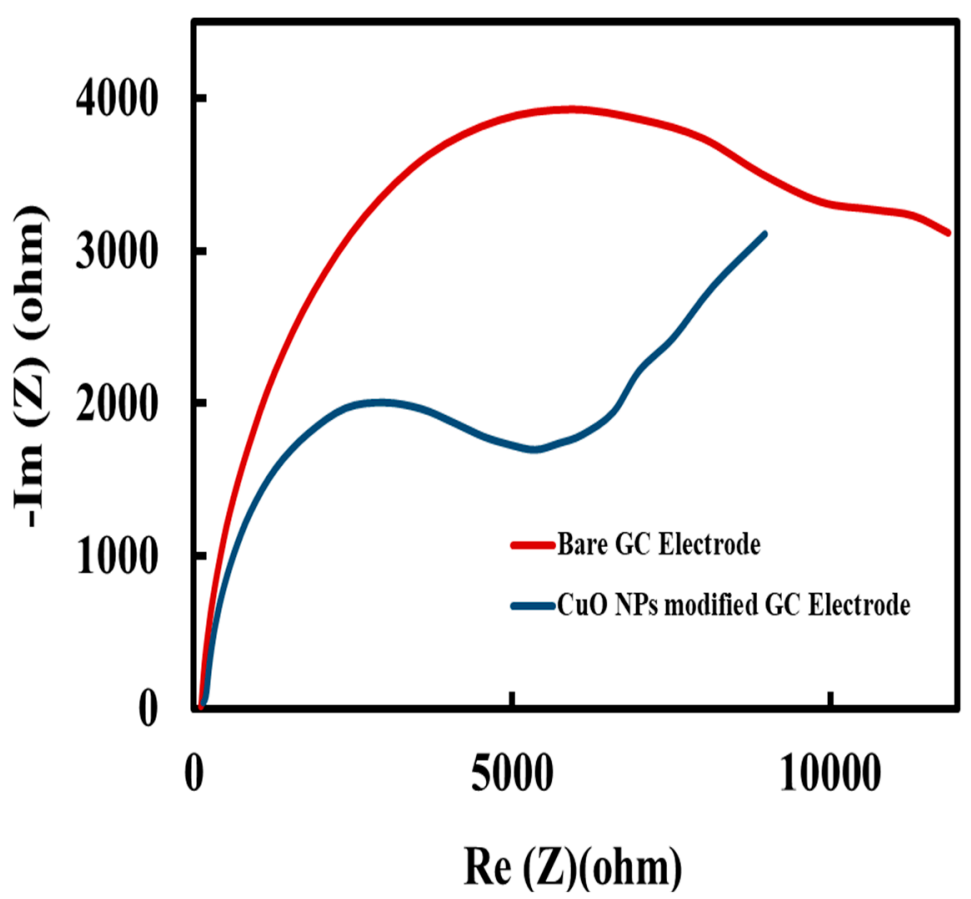

Figure 7. Nyquist plot of bare GC and the synthesized CuO NPs modified GC electrode, respectively. 


\section{Conclusions}

In this study, $\mathrm{CuO}$ NPs were successfully synthesized using chia seed extract through an eco-friendly approach. The synthesized $\mathrm{CuO}$ NPs were characterized using FESEM, EDX, UV-vis spectroscopy, XRD, and XPS. The advantages of this work lie in the simple, fast, efficient, and eco-friendly synthesis of the $\mathrm{CuO}$ NPs using an aqueous extract of chia seeds, without the use of any hazardous reagents or tedious and expensive methods. The antioxidant compounds present in chia seeds extract acted as reducing and capping agents in the synthesis of the CuO NPs. The characterization outcomes show that the prepared $\mathrm{CuO}$ NPs were crystalline in nature, exhibited good electrical conductivity, and were high-purity MONPs. Additionally, the average synthesized nanoparticles' size was found to be $61.5 \mathrm{~nm}$. Thus, the green $\mathrm{CuO}$ synthesized using chia seed extract could have potential for application in electrochemical sensing, as well as other environmental and antimicrobial applications.

Funding: This research was not receive any funding.

Institutional Review Board Statement: Not applicable.

Informed Consent Statement: Not applicable.

Data Availability Statement: Data are contained within the article.

Acknowledgments: The author gratefully appreciates the support of King Abdul-Aziz City for Science and Technology (KACST) for the conduction of the FESEM characterization. The authors also thank Aisha Ganash of King Abdul Aziz University for assisting with the electrochemical measurements. The contributions by the Chemistry Department at Taif University and the Ministry of Education in the Kingdom of Saudi Arabia are also acknowledged.

Conflicts of Interest: The authors declare no conflict of interest.

\section{References}

1. Zaheer, Z.; Aisha, A.-A.; Aazam, E.S. Adsorption of methyl red on biogenic Ag@ Fe nanocomposite adsorbent: Isotherms, kinetics and mechanisms. J. Mol. Liq. 2019, 283, 287-298. [CrossRef]

2. Verma, M.; Gupta, V.K.; Dave, V.; Chandra, R.; Prasad, G. Synthesis of sputter deposited CuO nanoparticles and their use for decontamination of 2-chloroethyl ethyl sulfide (CEES). J. Colloid Interface Sci. 2015, 438, 102-109. [CrossRef] [PubMed]

3. Mohmood, I.; Lopes, C.; Lopes, I.; Ahmad, I.; Duarte, A.; Pereira, E. Nanoscale materials and their use in water contaminants removal-a review. Environ. Sci. Pollut. Res. 2013, 20, 1239-1260. [CrossRef]

4. Sharma, P.; Bhargava, M. Applications and characteristics of nanomaterials in industrial environment. Res. Dev. 2013, 3, 63-72.

5. Nagajyothi, P.; Muthuraman, P.; Sreekanth, T.; Kim, D.H.; Shim, J. Green synthesis: In-vitro anticancer activity of copper oxide nanoparticles against human cervical carcinoma cells. Arab. J. Chem. 2017, 10, 215-225. [CrossRef]

6. Al-Qasmi, N.; Al-Gethami, W.; Saleh, D.; Abuziad, A. A Sustainable Approach for the Synthesis of Metallic Nanoparticles and its Application as Antimicrobial Agents. J. Mater. Res. Technol. 2020, 9, 13036-13042. [CrossRef]

7. Pachaiappan, R.; Rajendran, S.; Show, P.L.; Manavalan, K.; Naushad, M. Metal/metal oxide nanocomposites for bactericidal effect: A review. Chemosphere 2021, 272, 128607. [CrossRef]

8. Li, N.; He, Y.-L.; Yi, Z.-Z.; Gao, L.; Zhai, F.-R.; Chattopadhyay, K. Multiple-metal-doped Fe3O4@Fe2O3 nanoparticles with enhanced photocatalytic performance for methyl orange degradation under UV/solar light irradiation. Ceram. Int. 2020, 46, 19038-19045. [CrossRef]

9. Al-Qasmi, N.; Soomro, M.T.; Aslam, M.; Rehman, A.U.; Ali, S.; Danish, E.Y.; Ismail, I.M.; Hameed, A. The efficacy of the ZnO: $\alpha-\mathrm{Fe}_{2} \mathrm{O}_{3}$ composites modified carbon paste electrode for the sensitive electrochemical detection of loperamide: A detailed investigation. J. Electroanal. Chem. 2016, 783, 112-124. [CrossRef]

10. Verma, B.; Balomajumder, C. Synthesis of magnetic nickel ferrites nanocomposites: An advanced remediation of electroplating wastewater. J. Taiwan Inst. Chem. Eng. 2020, 112, 106-115. [CrossRef]

11. El-El-Kemary, M.; Nagy, N.; El-Mehasseb, I. Nickel oxide nanoparticles: Synthesis and spectral studies of interactions with glucose. Mater. Sci. Semicond. Process. 2013, 16, 1747-1752. [CrossRef]

12. Chandra, S.; Kumar, A.; Tomar, P.K. Synthesis and characterization of copper nanoparticles by reducing agent. J. Saudi Chem. Soc. 2014, 18, 149-153. [CrossRef]

13. Usman, M.S.; Ibrahim, N.A.; Shameli, K.; Zainuddin, N.; Yunus, W.M.Z.W. Copper Nanoparticles Mediated by Chitosan: Synthesis and Characterization via Chemical Methods. Molecules 2012, 17, 14928-14936. [CrossRef]

14. Khan, A.; Rashid, A.; Younas, R.; Chong, R. A chemical reduction approach to the synthesis of copper nanoparticles. Int. Nano Lett. 2016, 6, 21-26. [CrossRef] 
15. Ahmed, K.; Yasmin, F.; Hussain, N. Green synthesis of nickle nanoparticles by using plant leaf extracts as reducing agent. Sci. Int. 2016, 28, 2511.

16. Joshi, N.; Pathak, A.; Anupam, R.; Jain, N.; Singh, J.; Upadhyaya, C.P. A Rapid and Efficient Biosynthesis of Metallic Nanoparticles Using Aqueous Extract of Chia (Salvia hispanica L.) Seeds. BioNanoScience 2019, 9, 893-902. [CrossRef]

17. Gnanavel, V.; Palanichamy, V.; Roopan, S.M. Biosynthesis and characterization of copper oxide nanoparticles and its anticancer activity on human colon cancer cell lines (HCT-116). J. Photochem. Photobiol. B Biol. 2017, 171, 133-138. [CrossRef]

18. Mali, S.C.; Raj, S.; Trivedi, R. Biosynthesis of copper oxide nanoparticles using Enicostemma axillare (Lam.) leaf extract. Biochem. Biophys. Rep. 2019, 20, 100699.

19. Veisi, H.; Karmakar, B.; Tamoradi, T.; Hemmati, S.; Hekmati, M.; Hamelian, M. Biosynthesis of CuO nanoparticles using aqueous extract of herbal tea (Stachys Lavandulifolia) flowers and evaluation of its catalytic activity. Sci. Rep. 2021, 11, 1-13.

20. Keabadile, O.P.; Aremu, A.O.; Elugoke, S.E.; Fayemi, O.E. Green and Traditional Synthesis of Copper Oxide NanoparticlesComparative Study. Nanomaterials 2020, 10, 2502. [CrossRef]

21. Siddiqui, V.U.; Ansari, A.; Chauhan, R.; Siddiqi, W.A. Green synthesis of copper oxide (CuO) nanoparticles by Punica granatum peel extract. Mater. Today Proc. 2021, 36, 751-755. [CrossRef]

22. Badawy, A.A.; Abdelfattah, N.A.; Salem, S.S.; Awad, M.F.; Fouda, A. Efficacy Assessment of Biosynthesized Copper Oxide Nanoparticles (CuO-NPs) on Stored Grain Insects and Their Impacts on Morphological and Physiological Traits of Wheat (Triticum aestivum L.) Plant. Biology 2021, 10, 233. [CrossRef]

23. Naika, H.R.; Lingaraju, K.; Manjunath, K.; Kumar, D.; Nagaraju, G.; Suresh, D.; Nagabhushana, H. Green synthesis of CuO nanoparticles using Gloriosa superba L. extract and their antibacterial activity. J. Taibah Univ. Sci. 2015, 9, 7-12. [CrossRef]

24. Al-Johani, B.; Khan, A.N.; Alamshany, Z.M.; Gull, M.; Azam, E.S.; Kosa, S.A.; Soomro, M.T. Synthesis, Electrochemical and Antimicrobial Activity of Colloidal Copper Nanoparticles. Biosci. Biotechnol. Res. Asia 2017, 14, 1259-1268. [CrossRef]

25. Arévalo, F.J.; Osuna-Sánchez, Y.; Sandoval-Cortés, J.; Di Tocco, A.; Granero, A.M.; Robledo, S.N.; Zon, M.A.; Vettorazzi, N.R.; Martínez, J.L.; Segura, E.P.; et al. Development of an electrochemical sensor for the determination of glycerol based on glassy carbon electrodes modified with a copper oxide nanoparticles/multiwalled carbon nanotubes/pectin composite. Sens. Actuators B Chem. 2017, 244, 949-957. [CrossRef]

26. Arvand, M.; Ardaki, M.S. Poly- 1 -cysteine/electrospun copper oxide nanofibers-zinc oxide nanoparticles nanocomposite as sensing element of an electrochemical sensor for simultaneous determination of adenine and guanine in biological samples and evaluation of damage to dsDNA and DNA purine bases by UV radiation. Anal. Chim. Acta 2017, 986, 25-41. [PubMed]

27. Rafique, M.; Shafiq, F.; Gillani, S.S.A.; Shakil, M.; Tahir, M.B.; Sadaf, I. Eco-friendly green and biosynthesis of copper oxide nanoparticles using Citrofortunella microcarpa leaves extract for efficient photocatalytic degradation of Rhodamin B dye form textile wastewater. Optik 2020, 208, 164053. [CrossRef]

28. Reverberi, A.P.; Salerno, M.; Lauciello, S.; Fabiano, B. Synthesis of Copper Nanoparticles in Ethylene Glycol by Chemical Reduction with Vanadium (+2) Salts. Materials 2016, 9, 809. [CrossRef]

29. Botsa, S.M.; Dharmasoth, R.; Basavaiah, K. A facile synthesis of $\mathrm{Cu}_{2} \mathrm{O}$ and $\mathrm{CuO}$ nanoparticles via sonochemical assisted method. Curr. Nanosci. 2019, 15, 209-213. [CrossRef]

30. Singh, A.V.; Patil, R.; Anand, A.; Milani, P.; Gade, W. Biological Synthesis of Copper Oxide Nano Particles Using Escherichia coli. Curr. Nanosci. 2010, 6, 365-369. [CrossRef]

31. Honary, S.; Barabadi, H.; Gharaei-Fathabad, E.; Naghibi, F. Green synthesis of copper oxide nanoparticles using Penicillium aurantiogriseum, Penicillium citrinum and Penicillium wakasmanii. Dig. J. Nanomater. Biostruct. 2012, 7, 999-1005.

32. Kumar, P.V.; Shameem, U.; Kollu, P.; Kalyani, R.L.; Pammi, S.V.N. Green synthesis of copper oxide nanoparticles using Aloe vera leaf extract and its antibacterial activity against fish bacterial pathogens. BioNanoScience 2015, 5, 135-139. [CrossRef]

33. Taghavi Fardood, S.; Ramazani, A. Green synthesis and characterization of copper oxide nanoparticles using coffee powder extract. J. Nanostruct. 2016, 6, 167-171.

34. Okpara, E.C.; Fayemi, O.E. Comparative study of spectroscopic and cyclic voltammetry properties of CuONPs from citrus peel extracts. Mater. Res. Express 2019, 6, 105056. [CrossRef]

35. Ong, H.R.; Khan, M.M.R.; Ramli, R.; Du, Y.; Xi, S.; Yunus, R.M. Facile synthesis of copper nanoparticles in glycerol at room temperature: Formation mechanism. RSC Adv. 2015, 5, 24544-24549. [CrossRef]

36. Chen, T.-W.; Rajaji, U.; Chen, S.-M.; Muthumariyappan, A.; Al Mogren, M.M.; Ramalingam, R.J.; Hochlaf, M. Facile synthesis of copper(II) oxide nanospheres covered on functionalized multiwalled carbon nanotubes modified electrode as rapid electrochemical sensing platform for super-sensitive detection of antibiotic. Ultrason. Sonochem. 2019, 58, 104596. [CrossRef] [PubMed]

37. Yoo, C.H.; Kim, T.W. Effect of thermal annealing on the structural and optical properties of $\mathrm{CuO}$ nanocrystals formed on $\mathrm{Al}_{2} \mathrm{O}_{3}$ substrates using spin coating. J. Ceram. Process. Res. 2011, 12, 606. 